\title{
Brain MR Imaging Findings in Woodhouse-Sakati Syndrome
}

\author{
(D)A.H. Abusrair, (D) B. Bohlega, (D)A. Al-Semari, (D)F.S. Al-Ajlan, (DK. Al-Ahmadi, (D)B. Mohamed, and (D)A. AlDakheel
}

\begin{abstract}
BACKGROUND AND PURPOSE: Woodhouse-Sakati syndrome is a rare autosomal recessive disorder characterized by hypogonadism, alopecia, diabetes mellitus, and progressive extrapyramidal signs. The disease is caused by biallelic pathogenic variants in the DCAF77 gene. The purpose of this study was to describe the spectrum of brain MR imaging abnormalities in Woodhouse-Sakati syndrome.
\end{abstract}

MATERIALS AND METHODS: We reviewed brain MR images of 26 patients with a clinical and genetic diagnosis of Woodhouse-Sakati syndrome (12 males, 14 females; age range, 16-45 years; mean age, 26.6 years). Follow-up studies were conducted for 6 patients.

RESULTS: All patients had abnormal MR imaging findings. The most common abnormalities were a small pituitary gland (76.9\%), pronounced basal ganglia iron deposition (73\%), and white matter lesions in 69.2\%. White matter lesions showed frontoparietal and periventricular predominance. All white matter lesions spared subcortical U-fibers and were nonenhanced. Prominent perivascular spaces (15.3\%) and restricted diffusion in the splenium of the corpus callosum (7.6\%) were less frequent findings. Follow-up studies showed expansion of white matter lesions with iron deposition further involving the red nucleus and substantia nigra. Older age was associated with a more severe degree of white matter lesions $(P<.001)$.

CONCLUSIONS: Small pituitary gland, accentuated iron deposition in the globus pallidus, and nonenhancing frontoparietal/periventricular white matter lesions were the most noted abnormalities seen in our cohort. The pattern and extent of these findings were observed to correlate with older age, reflecting a possible progressive myelin destruction and/or axonal loss. The presence of pituitary hypoplasia and white matter lesions can further distinguish Woodhouse-Sakati syndrome from other neurodegenerative diseases with brain iron accumulation subtypes.

ABBREVIATIONS: NBIA = neurodegenerative diseases with brain iron accumulation; WSS = Woodhouse-Sakati syndrome; SNHL = sensorineural hearing loss

I n 1983, Woodhouse and Sakati ${ }^{1}$ described an autosomal recessive syndrome of hypogonadism, alopecia, diabetes mellitus, deafness, and extrapyramidal signs in several consanguineous Saudi families. ${ }^{2-5}$ To date, a total of 76 affected individuals, belonging to 32 families, have been reported in the literature. ${ }^{2}$ While most cases are from Saudi Arabia and the Middle East, ${ }^{2,3}$ affected individuals from other ethnicities have been reported. ${ }^{6-11}$ Homozygous pathogenic variants in the DCAF17 gene (formerly known as C2ORf37), allocated to chromosome 2q31.1, were discovered as the underlying cause of Woodhouse-Sakati syndrome

Received June 6, 2018; accepted after revision September 29.

From the Departments of Neurosciences (A.H.A., S.B., A.A.-S., F.S.A.-A., B.M., A.A.) and Radiology (K.A.-A.), King Faisal Specialist Hospital \& Research Center,

Riyadh, Saudi Arabia.

Please address correspondence to Saeed Bohlega, MD, Department of Neurosciences, King Faisal Specialist Hospital \& Research Center, PO Box 3354, Riyadh 11211, Saudi Arabia; e-mail: boholega@kfshrc.edu.sa; @Aliabusrair

三 Indicates article with supplemental on-line table.

http://dx.doi.org/10.3174/ajnr.A5879
(WSS). ${ }^{3,12}$ The pathogenesis of the syndrome and the underlying gene remain unclear.

The affected individuals have distinctive dysmorphic features characterized by a long triangular face, prominent nasal bridge, and hypertelorism. ${ }^{1,2}$ The disease has a progressive nature, with predominant neuroendocrine manifestations that become increasingly more frequent during adolescence and early adulthood. ${ }^{4}$ Virtually all individuals will have the endocrine finding of progressive childhood-onset hair thinning as the initial manifestation of the disease. ${ }^{2}$ All patients have hypogonadism of a mixed nature. ${ }^{13}$ More than half of individuals will have variable neurologic manifestations, including progressive extrapyramidal movements (dystonic spasms with dystonic posturing, dysarthria, and dysphagia), bilateral postlingual sensorineural hearing loss, and mild intellectual disability. ${ }^{2-5}$ Less frequently recognized manifestations include seizures, keratoconus, and electrocardiographic abnormalities. $^{2,4}$

The disease is characterized by wide phenotypic variabilities in 
the setting of white matter changes on brain images. ${ }^{2,14}$ There is no descriptive analysis of these changes, apart from very limited descriptions in some of the reported cases.

\section{MATERIALS AND METHODS Patients}

This was a single-institution analysis of all available brain studies for patients with a clinically and genetically confirmed diagnosis of WSS (26 patients; 12 males, 14 females; age range, 16-45 years; mean age, 26.6 years). Subjects were recruited from June 2009 to September 2017.

All studies were performed at King Faisal Specialist Hospital \& Research Center, a tertiary care referral center in Riyadh, Saudi Arabia.

Proband molecular genetic testing confirmed homozygous pathogenic variants in DCAF17 in all participants. The institutional review board approved the study, with all patients providing written informed consent.

\section{Clinical Assessment}

A focused clinical examination with emphasis on neurologic involvement was conducted in all participants in an outpatient setting at the time of MR imaging acquisition. Muscle tone was rated using the Burke Fahn-Marsden Dystonia Rating Scale-Movement. ${ }^{15}$ Dystonia was defined as involuntary sustained or intermittent muscle contractions causing abnormal postures and/or repetitive movements. The involvement of 1 body part (cervical, mouth and jaw, larynx, limb) was labeled "focal dystonia." Dystonia was defined as "multifocal" if at least 2 noncontiguous regions were affected, and "segmental," if $\geq 2$ contiguous regions were involved. Sensorineural hearing loss was confirmed through standardized audiologic assessment.

\section{Brain Imaging Protocol}

All MR imaging studies in our series, including those shown in the figures, are representative cases that were obtained using a $1.5 \mathrm{~T}$ MR imaging scanner (Genesis Signa; GE Healthcare, Milwaukee, Wisconsin) with parameters that are widely accepted. Sequence acquisitions included sagittal T1-weighted images $(\mathrm{TR} / \mathrm{TE}=$ $300-600 / 30 \mathrm{~ms})$; axial T1- and T2-weighted images $(\mathrm{TR} / \mathrm{TE}=$ $3000-7000 / 90 \mathrm{~ms}$ ); T2*-weighted gradient recalled-echo images ( $\mathrm{TE}=750 / 50 \mathrm{~ms})$; fluid-attenuated inversion recovery sequences $(\mathrm{TR} / \mathrm{TE}=8000-10,000 / 140 \mathrm{~ms}$; $\mathrm{TI}=2200 \mathrm{~ms})$; and axial and coronal T1-weighted images with intravenous gadolinium. DWI was acquired with a single-shot EPI spin-echo sequence with TR/ $\mathrm{TE}=8000 / 87.6 \mathrm{~ms} ; \mathrm{FOV}=26 \times 26 \mathrm{~cm}^{2} ;$ matrix $=128 \times 128 ;$

NEX 2, 24 sections; a 5-mm section thickness; and a $0.3-\mathrm{mm}$ section gap. Eight patients underwent a special pituitary MR imaging protocol [T1- and T2-weighted spin-echo coronal and sagittal sections using a small FOV $(20 \times 25 \mathrm{~cm})$ and thin slices $(3$ $\mathrm{mm})$ ] covering the sellar and parasellar regions.

In patients with craniocervical dystonia, head motion was minimized by firm sponge wedges around the head and restraining straps during and between the acquisition of images.

\section{MR Imaging Analysis}

MR images were reviewed by an expert, board-certified neuroradiologist (K.A.-A.) who was blinded to patients' clinical findings.
This was followed by a consensus agreement from the investigating group. The studies were systematically evaluated for any abnormalities of both cortical and subcortical anatomic white and gray matter structures.

White matter lesions were described according to their site, shape, confluency, and multifocality. ${ }^{16}$ The extent of these changes was subjectively graded and described as follows: absent $(-)$; mild (predominantly scattered lesions or confluent periventricular) $(+)$; moderate (patchy scattered) $(++)$; or severe (predominantly diffuse, vanishing lesions) $(+++)$. All 26 patients were studied with intravenous contrast material to analyze abnormal enhancement.

The pituitary gland was assessed with focus on the dimensions and size of the gland. The volume of the pituitary gland was determined by applying the cubic formula (length $\times$ width $\times$ height). ${ }^{17,18}$ Pituitary length was estimated from the maximum anteroposterior diameter parallel to the floor of the sella on the sagittal plane. The height was measured in sagittal and coronal sections, with midline measurement of the distance between the superior and inferior borders of the pituitary gland. The width of the gland was estimated with the 2 highest points on the lateral edges of the plateau of the fossa floor in the midcoronal plane. Measurements were compared with values of matched groups for both age and sex. In addition, the sellar and parasellar structures were observed for any abnormal pathology.

Areas rich in iron were defined on the basis of a standard protocol, ${ }^{14}$ and their appearance was described as hypointense on T2-weighted/FLAIR sequences, isointense on T1 sequences, and "blooming" hypointense on $\mathrm{T} 2{ }^{\star}$-weighted acquisitions (gradient-echo sequences). Areas of focus included the caudate nucleus, putamen, globus pallidus, thalamus, red nucleus, and substantia nigra. Abnormal signals were addressed as present $(+)$ or absent $(-)$. MR spectroscopy was performed in 4 patients.

Diffusion restriction was defined as hyperintense on DWI, with low apparent diffusion coefficient map values.

Prominent perivascular spaces were described base on three characteristic anatomic locations, ${ }^{19}$ as type I: along the lenticulostriate arteries entering the basal ganglia through the anterior perforated substance; type II: along the path of the perforating medullary arteries as they enter the cortical gray matter over the high convexities and extend into the white matter; and type III: along the midbrain.

An additional area of focus was the internal auditory canal and its contents for any abnormal structural or signal abnormalities.

\section{Follow-Up Studies}

Six of 26 patients had repeat MR imaging, performed $2-5$ years (mean duration, 3.2 years) from the initial study to assess radiologic progression.

\section{Statistical Analysis}

Data collection and analysis were performed using Research Electronic Data Capture (REDCap) tools and JMP statistical software, Version 14 (SAS Institute, Cary, North Carolina). REDCap is a secure web application for building and managing on-line surveys and data bases. Descriptive statistics for categoric variables are reported using frequencies and percentages. The Spearman test

AJNR Am J Neuroradiol 39:2256-62 Dec 2018 www.ajnr.org 2257 


\begin{tabular}{|c|c|c|c|c|c|c|c|c|}
\hline \multirow[b]{2}{*}{ Family } & \multirow[b]{2}{*}{ Sex } & \multirow[b]{2}{*}{ Age (Yr) } & \multicolumn{3}{|c|}{ Neurologic } & \multicolumn{3}{|c|}{ Radiologic } \\
\hline & & & Dystonia & SNHL & Seizure & WM Changes & ID & Pituitary \\
\hline \multirow[t]{2}{*}{1} & $\mathrm{~F}$ & 18 & Focal & - & - & Mild & - & Small \\
\hline & $M$ & 19 & - & - & + & Absent & + & Small \\
\hline \multirow[t]{3}{*}{2} & $\mathrm{~F}$ & 29 & Generalized & - & - & Severe & + & Normal \\
\hline & $\mathrm{F}$ & 38 & Focal & + & - & Moderate & + & Small \\
\hline & $\mathrm{F}$ & 35 & Focal & + & - & Mild & + & Small \\
\hline \multirow[t]{2}{*}{3} & $\mathrm{~F}$ & 37 & Focal & - & - & Severe & + & Small \\
\hline & $M$ & 45 & Generalized & + & - & Severe & + & Small \\
\hline \multirow[t]{2}{*}{4} & M & 22 & Focal & - & - & Mild & + & Normal \\
\hline & M & 24 & Generalized & - & - & Mild & + & Normal \\
\hline \multirow[t]{5}{*}{5} & M & 23 & - & - & - & Mild & - & Small \\
\hline & $\mathrm{F}$ & 21 & - & - & - & Mild & + & Small \\
\hline & M & 16 & - & - & - & Mild & - & Small \\
\hline & M & 26 & Generalized & + & - & Mild & + & Normal \\
\hline & M & 21 & - & + & + & Absent & + & Normal \\
\hline \multirow[t]{2}{*}{6} & M & 20 & Generalized & - & - & Mild & - & Small \\
\hline & $\mathrm{F}$ & 21 & - & - & - & Absent & + & Small \\
\hline \multirow[t]{5}{*}{7} & $\mathrm{~F}$ & 32 & Multisegmental & - & - & Mild & + & Small \\
\hline & $\mathrm{F}$ & 22 & Focal & - & - & Absent & - & Small \\
\hline & $\mathrm{F}$ & 35 & Focal & - & + & Severe & + & Small \\
\hline & M & 21 & Multisegmental & + & - & Absent & + & Small \\
\hline & $\mathrm{F}$ & 27 & Focal & + & - & Absent & + & Small \\
\hline 8 & $M$ & 16 & - & - & - & Absent & - & Small \\
\hline 9 & $\mathrm{~F}$ & 41 & Generalized & - & - & Moderate & + & Small \\
\hline 10 & M & 37 & Multisegmental & + & - & Moderate & + & Small \\
\hline 11 & $\mathrm{~F}$ & 17 & Multisegmental & - & - & Absent & + & Small \\
\hline 12 & $\mathrm{~F}$ & 29 & - & - & - & Mild & - & Normal \\
\hline
\end{tabular}

Note:-SNHL indicates sensorineural hearing loss; ID, iron deposition; +, present; -, absent.

was used to assess the correlation between quantitative MR imaging severity (at the initial test) and age. $P \leq .05$ was considered statistically significant.

\section{RESULTS}

\section{Patients}

The clinical characteristics of patients are summarized in Table 1. Dystonia was the most common neurologic manifestation (18 patients, $69.2 \%$ ), followed by sensorineural hearing loss and seizures seen in $30.7 \%$ and $11.5 \%$, respectively. Focal dystonia (44\%) was more common than generalized (23\%) and multisegmental (15.3\%) dystonia.

\section{Description of MR Imaging Findings}

Table 2 summarizes the detailed neuroimaging characteristics in our series.

A partially empty sella and a small pituitary gland were seen in 20 patients (76.9\%); they were the most common MR imaging abnormalities in our cohort (Fig 1). Patients with WSS had a significantly smaller mean pituitary gland volume of $173 \pm 91$ $\mathrm{mm}^{3}$ compared with healthy control subjects with a mean of $480 \pm 85 \mathrm{~mm}^{3}(P<.005)$. Six patients $(23 \%)$ had normal pituitary gland volume. The pituitary stalk varied in size, but most of the affected individuals had a relatively small stalk. No abnormal suprasellar and parasellar structures were noted.

Evidence of iron deposition in the globus pallidus was observed in 19 patients (73\%) (Fig $2 A-C)$. Involvement of the substantia nigra and red nucleus was noted in 6 patients (23\%) (Fig 2D). MR spectroscopy in 4 patients demonstrated normal major metabolite peaks. Despite the clinical finding of generalized or focal dystonia, 3 patients showed no evidence of iron deposition on MR imaging.

White matter abnormalities on T2-weighted and FLAIR images were seen in 18 patients $(69.2 \%)$. These changes varied in terms of distribution and extension (Fig 3). Extension of WM changes was characterized by a periventricular and frontoparietal predominance (Fig 4A, - B). Involvement of other subcortical (basal ganglia, thalamus) and infratentorial structures was seen in 3 patients (11.5\%) (Fig 4C, $-D$ ). Older age was associated with more severe white matter lesions $(r=0.71, P<.001)$. All white matter lesions were nonenhancing and spared the U-fibers.

Prominent perivascular spaces were noted in 4 patients (15.3\%), ranging from type 1 to type 3 (Fig 5). Diffusion restriction involving the splenium of the corpus callosum was noted in 2 patients (Fig. 6). One patient had multiple subcortical diffusion restrictions.

Follow-up images were available for 6 patients, with a mean follow-up of 3.2 years from the initial studies (range, 2-5 years). Progression of WM extension and iron deposition were noted in all 6 patients.

\section{DISCUSSION}

Our study revealed variable abnormalities in all 26 patients, including some features described in prior reports (On-line Table). The observations of a small hypophysis, prominent perivascular spaces, transient signal changes of the splenium of the corpus callosum, and the progressive radiologic involvement are previously undescribed characteristics of the disease.

Endocrine involvement in WSS is invariable, and virtually all cases are associated with childhood-onset hair thinning with 


\begin{tabular}{|c|c|c|c|c|c|c|c|c|c|c|c|c|}
\hline \multirow[b]{3}{*}{ Patient } & \multirow{3}{*}{$\begin{array}{l}\text { Sex/Age } \\
\text { (yr) }\end{array}$} & & & & & & \multicolumn{5}{|c|}{ Descriptive Features on MRI } & \multirow[b]{3}{*}{ Comments } \\
\hline & & \multicolumn{5}{|c|}{ White Matter } & \multicolumn{3}{|c|}{ Iron Deposition } & \multirow{2}{*}{$\begin{array}{l}\text { Pituitary } \\
\text { Atrophy }\end{array}$} & \multirow{2}{*}{$\begin{array}{l}\text { Diffusion } \\
\text { Restriction }\end{array}$} & \\
\hline & & Frontal & Parietal & Temporal & Occipital & Infratentorial & Caudate & Putamen & $\mathrm{RN} / \mathrm{SN}$ & & & \\
\hline 1 & $F / 18$ & + & + & - & + & - & - & - & - & + & + & - \\
\hline 2 & $M / 19$ & - & - & - & - & - & - & + & - & + & - & Initial study showed no iron deposition \\
\hline 3 & $F / 29$ & +++ & +++ & - & - & - & + & + & + & - & - & $\begin{array}{l}\text { Extension of iron deposition on } \\
\text { follow-up study }\end{array}$ \\
\hline 4 & $F / 38$ & ++ & ++ & + & + & - & + & + & - & + & + & Prominent perivascular spaces \\
\hline 5 & $\mathrm{~F} / 35$ & + & + & + & - & - & - & + & - & - & - & Prominent perivascular spaces \\
\hline 6 & $\mathrm{~F} / 37$ & +++ & +++ & + & + & - & - & + & - & + & - & Calcification of the dentate nucleus \\
\hline 7 & $M / 45$ & +++ & +++ & + & + & - & + & + & - & + & + & Loss of corpus callosum volume \\
\hline 8 & $M / 22$ & + & + & - & - & - & - & + & - & + & - & - \\
\hline 9 & $M / 24$ & + & + & - & - & - & - & + & - & - & - & Prominent perivascular spaces \\
\hline 10 & $M / 23$ & + & + & - & - & - & - & - & - & + & - & - \\
\hline 11 & $F / 21$ & + & + & - & - & - & - & + & - & + & - & - \\
\hline 12 & $M / 16$ & + & + & - & - & - & - & - & - & + & - & Prominent perivascular spaces \\
\hline 13 & $M / 26$ & + & + & + & + & - & - & + & + & + & - & - \\
\hline 14 & $M / 21$ & - & - & - & - & - & - & + & + & - & - & - \\
\hline 15 & $M / 20$ & + & - & - & - & - & - & - & - & + & - & - \\
\hline 16 & $F / 21$ & - & - & - & - & - & - & + & + & + & - & - \\
\hline 17 & $\mathrm{~F} / 32$ & + & + & + & + & - & - & + & - & + & - & - \\
\hline 18 & $\mathrm{~F} / 22$ & - & - & - & - & - & - & - & - & + & - & - \\
\hline 19 & $\mathrm{~F} / 35$ & +++ & +++ & + & + & + & - & + & - & + & - & Pontine WM signal \\
\hline 20 & $M / 21$ & - & - & - & - & - & - & + & + & + & - & - \\
\hline 21 & $\mathrm{~F} / 27$ & - & - & - & - & - & - & + & - & + & - & - \\
\hline 22 & $M / 16$ & - & - & - & - & - & - & - & - & + & - & - \\
\hline 23 & $F / 41$ & ++ & ++ & + & + & - & + & + & + & + & - & - \\
\hline 24 & $M / 37$ & ++ & ++ & + & + & - & + & + & - & + & - & Dentate nucleus calcification \\
\hline 25 & $\mathrm{~F} / 17$ & - & - & - & - & - & - & + & - & - & - & - \\
\hline 26 & $F / 29$ & + & + & + & + & + & - & - & - & - & - & Cerebellar WM signal \\
\hline
\end{tabular}

Note:-RN indicates red nucleus; SN, substantia nigra; -, absent; +, mild (predominantly scattered lesions or confluent periventricular); ++, moderate (patchy scattered); +++ , severe (predominantly diffuse, vanishing lesions)

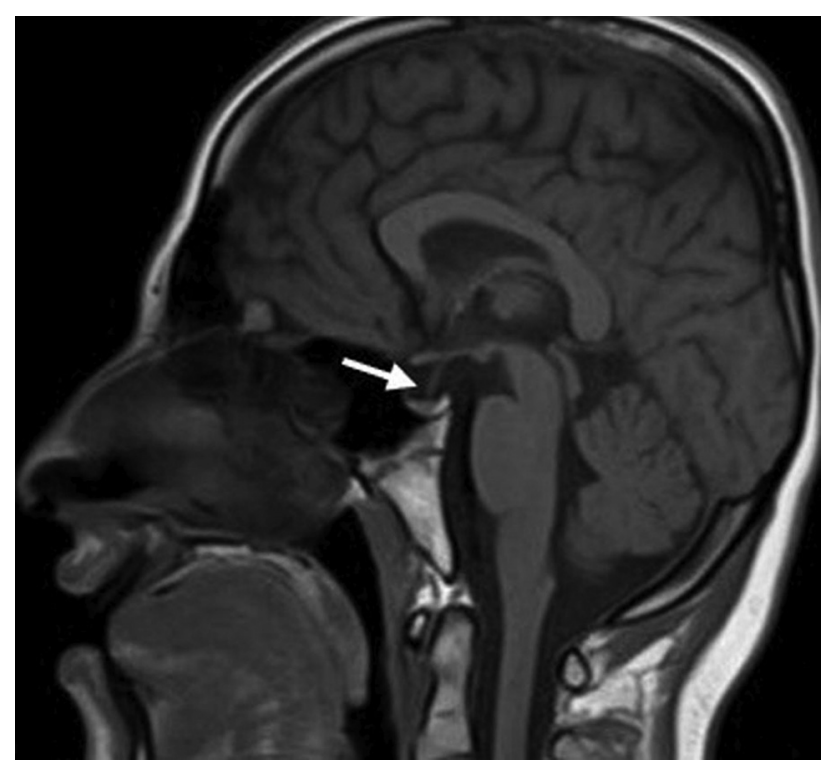

FIG 1. Sagittal T7-weighted MR imaging for patient 22 shows a partially empty sella and a small pituitary gland (arrow).

frontotemporal alopecia, hypogonadism, and decreased insulinlike growth factor-1. 2,4,13 Hypogonadism manifests as delayed puberty with a lack of secondary sexual characteristics. Hypogonadism is distinctive by mixed origin. Women tend to develop hypergonadotropic hypogonadism, while men have hypogonadotropic hypogonadism. ${ }^{13}$ Both sexes share an insufficient hypothalamic-pituitary response. ${ }^{2,4}$ Low insulin-like growth factor-1 and hypogonadism might be manifestations of a small hypophysis. Other endocrine manifestations, however, cannot be explained by pituitary hypoplasia. Hypothyroidism, reported in $30 \%$ of patients and usually observed after the age of $25,{ }^{2}$ is of a peripheral origin. Type 2 diabetes mellitus was seen in up to $66 \%$ of patients and has no clear underlying pathology. In addition, diabetes is inconsistent with the observed low insulin-like growth factor-1 values. The hypothesized mechanism for the onset of diabetes, similar to that of hypothyroidism, in the absence of an underlying autoimmunity, is likely related to gonadal dysgeneses. ${ }^{1,10}$

Pituitary hypoplasia in the setting of a genetically based syndrome has rarely been described. ${ }^{20}$ Reproductive defects, hypogonadism along with confluent white matter abnormalities, and a partially empty sella on MR imaging are features similar to those seen in Gordon Holmes syndrome and Boucher-Neuhäuser syndrome. Both disorders are autosomal recessive as well. ${ }^{21,22}$ Cerebellar involvement in both conditions and chorioretinal dystrophy in Neuhäuser syndrome are features distinct from those in WSS. $^{22,23}$

Diffuse cerebral white matter signal abnormalities are a feature of many inherited degenerative disorders. White matter changes might be the result of cerebral white matter degeneration, demyelination, or hypomyelination. Vascular leukoencephalopathies might cause multifocal white matter abnormalities in the early stages, which eventually progress into more confluent lesions in advanced stages. Vasculopathies are characterized by the almost invariable presence of additional multifocal lesions in the basal ganglia, thalami, and the brain stem. This cohort showed rare involvement of these structures. Hypomyelination disorders are characterized by less marked and more widespread T2 hyperintensity compared with that seen in our series. ${ }^{16}$ The finding of transient signal changes of the splenium of the corpus callosum is a feature that might be seen in demyelinating or vascular conditions. $^{24,25}$

Preservation of U-fibers in diffuse white matter disease has 


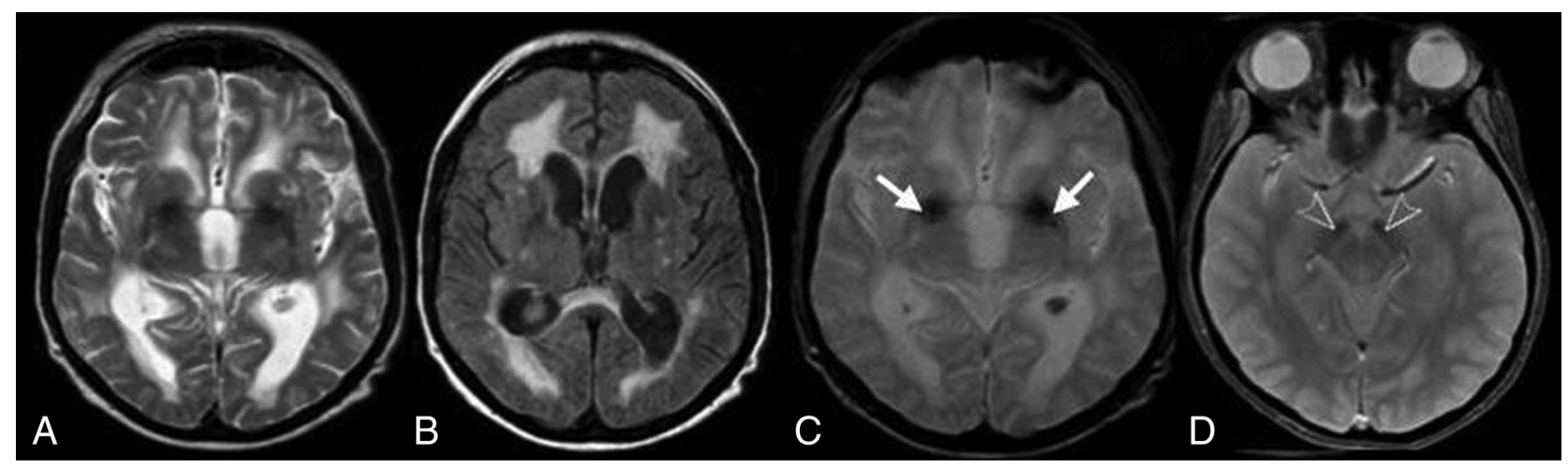

FIG 2. Axial T2-weighted (A), FLAIR (B), and T2* (C) MR images in case 11 show putaminal blooming artifacts (arrows) reflecting iron accumulation. An axial T2* MR image $(D)$ in case 3 shows iron deposition in the substantia nigra (arrowheads).
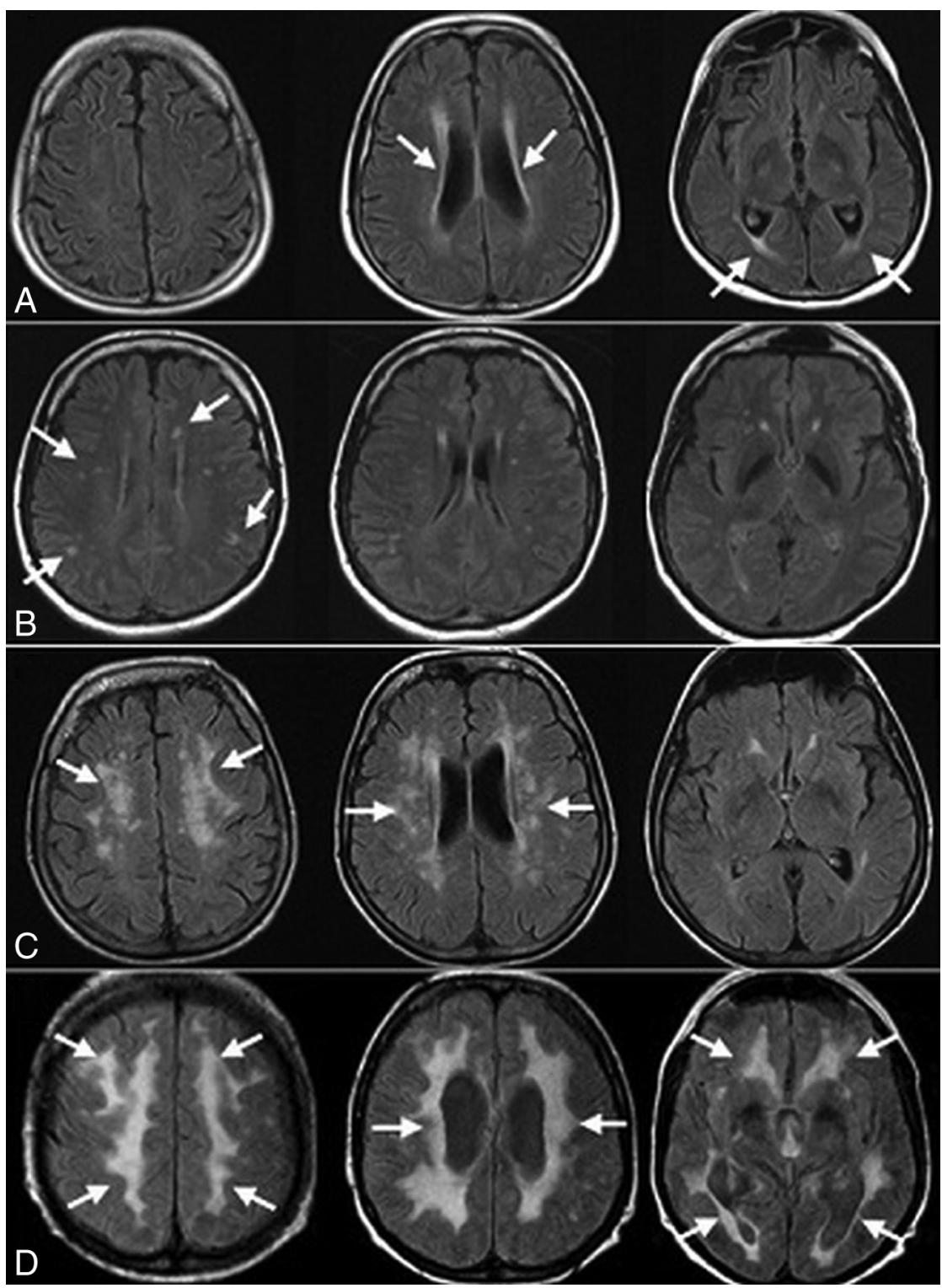

FIG 3. Axial FLAIR MR images show varying degrees of white matter lesions. Patients 1 and 26 (A and $B$ ) show a mild degree of white matter lesions, with faint periventricular ( $A$; arrows) and small scattered signal intensities ( $B$; arrows). In patient $4(C)$, images show patchy signal intensities (arrows), representing a moderate degree of white matter lesions. A more diffuse, vanishing high signal intensity (arrows) is seen in images (D) for patient 7. diagnostic utility. ${ }^{16}$ Alexander disease, metachromatic leukodystrophy, and Xlinked adrenoleukodystrophy are the most notable disorders with this distinctive feature. ${ }^{26-29}$ Our cohort revealed a variable degree of subcortical periventricular and frontoparietal prominence WM changes of a progressive nature. These findings are opposed to frontal and parieto-occipital prominence in Alexander disease and $\mathrm{X}$-linked adrenoleukodystrophy, respectively. ${ }^{16,26}$ In addition, contrast enhancement may be seen in both disorders and was not seen in any of our patients. Brain stem lesions, rarely seen in WSS, are a frequent feature of Alexander disease. $^{30}$

Although considered atypical, WSS shares some characteristics with neurodegenerative diseases with brain iron accumulation (NBIA). NBIA are a group of inherited neurologic disorders with hallmark clinical manifestations of progressive dystonia and spasticity in the setting of brain iron deposition ${ }^{31,32}$ and are characterized by symmetric accelerated iron deposition involving the gray matter nuclei (globus pallidus, substantia nigra, red nucleus, dentate nucleus, putamen, and thalamus). ${ }^{14}$ Iron deposition in the globus pallidus and, later in the disease, in the substantia nigra was observed in some of our patients. This feature has been described in neuroaxonal dystrophy, a rare progressive form of NBIA. ${ }^{14}$ Evidence of iron deposition may precede or follow the development of clinical symptoms in some NBIA, a characteristic also seen in our cohort. ${ }^{32}$ In comparison with other NBIA, extrapyramidal features in WSS consist of focal or multisegmental and, in some 


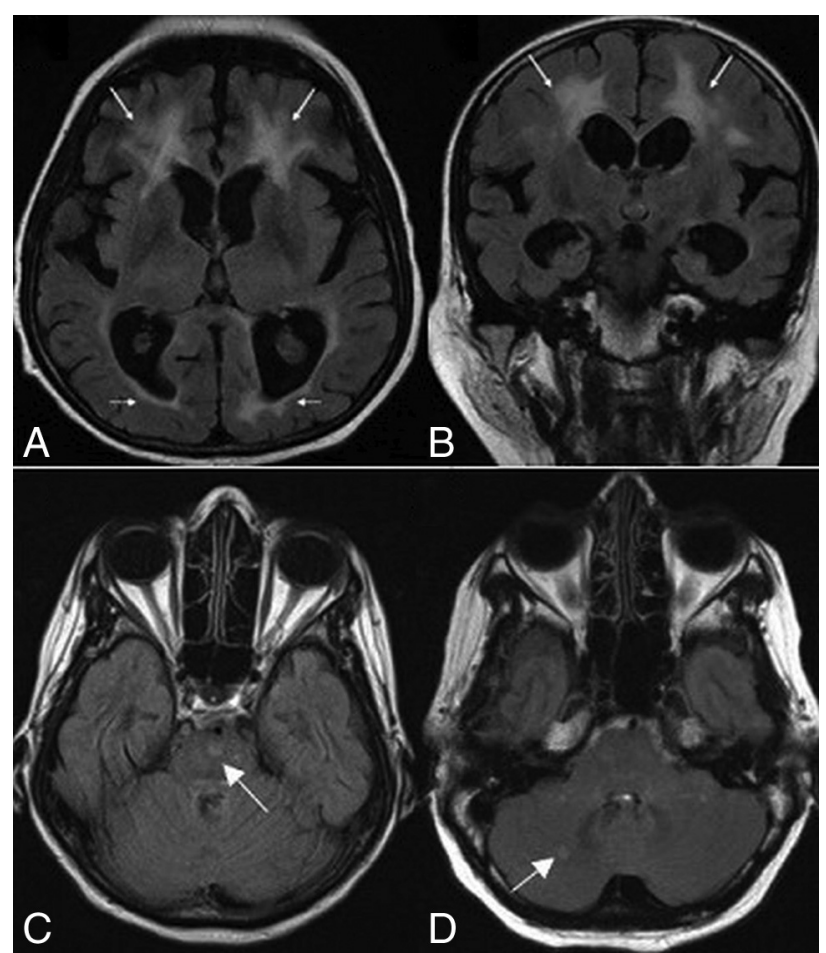

FIG 4. Axial $(A)$ and coronal (B) FLAIR MR images for case 24 show white matter changes with frontal predominance (arrows). Axial FLAIR images show signal intensities (arrows) involving the pons $(C)$ in patient 19 and the cerebellum $(D)$ in patient 26.
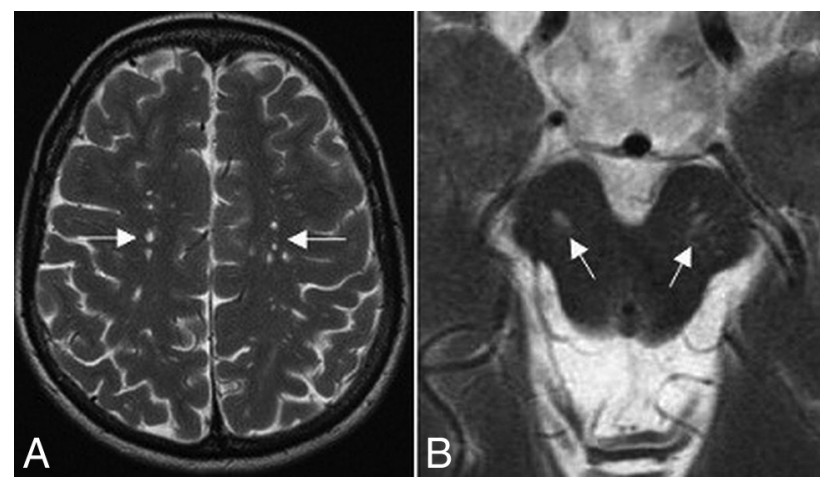

FIG 5. Axial T2 images show type I (A) and type III (B) prominent perivascular spaces.

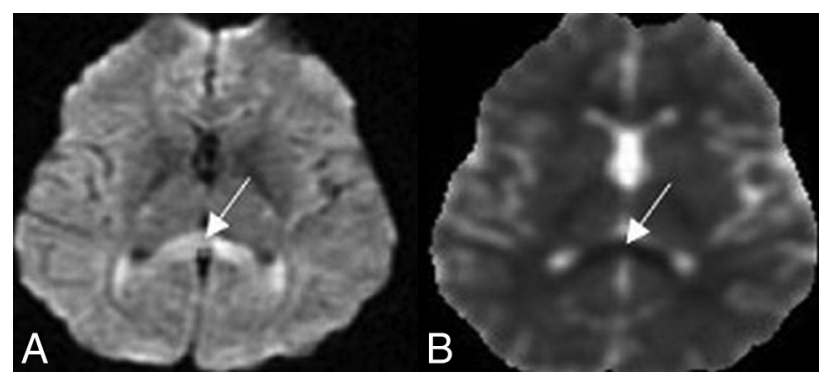

FIG 6. Axial DWI $(A)$ and $A D C$ map $(B)$ sequences show diffusion restriction involving the splenium of corpus callosum.

patients, generalized dystonia. ${ }^{5}$ The presence of white matter changes and a small hypophysis in the setting of brain iron accumulation is a major distinction between WSS and other NBIA subtypes.
Interfamilial and intrafamilial phenotypic variability is a wellrecognized feature of WSS. ${ }^{3,33}$ The spectrum of DCAF17 gene mutations has expanded, with 9 mutations reported in the literature to date. When one considered all known variants, DCAF17 was found to poorly correlate with the severity of the associated phenotypes. ${ }^{3}$ Our series revealed a similar discrepancy when correlating clinical features with neuroimaging findings. We found no correlation between iron deposition and neurologic involvement. Despite the clinical findings of generalized or focal dystonia, 3 patients showed no evidence of abnormal iron deposition on MR imaging.

Our study has several limitations. First, all participants were recruited at variable clinical stages of the disease. In addition, all follow-up studies were not systematically performed, with no specific time interval from the initial study. This feature would poorly characterize the rate of progression of the disease.

\section{CONCLUSIONS}

Small pituitary gland, accentuated iron deposition in the globus pallidus, and nonenhancing frontoparietal/periventricular WM changes are the most noted brain MR abnormalities in WSS. The presence of WM changes and pituitary involvement can further distinguish WSS from other NBIA subtypes. The progressive nature and variability of brain MR imaging findings that poorly correlate with the clinical characteristics, along with the lack of the underlying pathology, should be addressed in future studies.

\section{ACKNOWLEDGMENTS}

The authors acknowledge the patients and their families for their cooperation and participation in the study.

\section{REFERENCES}

1. Woodhouse NJ, Sakati NA. A syndrome of hypogonadism, alopecia, diabetes mellitus, mental retardation, deafness, and ECG abnormalities. J Med Genet 1983;20:216-19 CrossRef Medline

2. Bohlega SA, Alkuraya FS. Woodhouse-Sakati syndrome. 2016 Aug 4. In: Adam MP, Ardinger HH, Pagon RA, et al, eds. GeneReviews. https://www.ncbi.nlm.nih.gov/books/NBK378974/. Accessed May 16,2018

3. Alazami AM, Schneider SA, Bonneau D, et al. C2orf37 mutational spectrum in Woodhouse-Sakati syndrome patients. Clin Genet 2010;78:585-90 CrossRef Medline

4. Al-Semari A, Bohlega S. Autosomal-recessive syndrome with alopecia, hypogonadism, progressive extra-pyramidal disorder, white matter disease, sensory neural deafness, diabetes mellitus, and low IGF1. Am J Med Genet Part A 2007;143A:149-160

5. Schneider SA, Bhatia KP. Dystonia in the Woodhouse Sakati syndrome: a new family and literature review. Mov Disord 2008;23: 592-96 CrossRef Medline

6. Abdulla MC, Alazami AM, Alungal J, et al. Novel compound heterozygous frameshift mutations of C2orf37 in a familial Indian case of Woodhouse-Sakati syndrome. J Genet 2015;94:489-92 CrossRef Medline

7. Koshy G, Danda S, Thomas N, et al. Three siblings with WoodhouseSakati syndrome in an Indian family. Clin Dysmorphol 2008;17: 57-60 CrossRef Medline

8. Habib R, Basit S, Khan S, et al. A novel splice site mutation in gene C2orf37 underlying Woodhouse-Sakati syndrome (WSS) in a consanguineous family of Pakistani origin. Gene 2011;490:26-31 CrossRef Medline

9. Hdiji O, Turki E, Bouzidi N, et al. Woodhouse-Sakati syndrome:

AJNR Am J Neuroradiol 39:2256-62 Dec 2018 www.ajnr.org 
report of the first Tunisian family with the $\mathrm{C} 2$ orf 37 gene mutation. J Mov Disord 2016;9:120-23 CrossRef Medline

10. Rachmiel M, Bistritzer T, Hershkoviz E, et al. Woodhouse-Sakati syndrome in an Israeli-Arab family presenting with youth-onset diabetes mellitus and delayed puberty. Horm Res Paediatr 2011;75: 362-66 CrossRef Medline

11. Steindl KL, Alazami AM, Bhatia KP, et al. A novel C2orf37 mutation causes the first Italian cases of Woodhouse Sakati syndrome. Clin Genet 2010;78:594-97 CrossRef Medline

12. Alazami AM, Al-Saif A, Al-Semari A, et al. Mutations in C2orf37, encoding a nucleolar protein, cause hypogonadism, alopecia, diabetes mellitus, mental retardation, and extrapyramidal syndrome. Am J Hum Genet 2008;83:684-91 CrossRef Medline

13. Agopiantz M, Corbonnois P, Sorlin A, et al. Endocrine disorders in Woodhouse-Sakati syndrome: a systematic review of the literature. J Endocrinol Invest 2014;37:1-7 CrossRef Medline

14. Kruer MC, Boddaert N, Schneider A, et al. Neuroimaging features of neurodegeneration with brain iron accumulation. AJNR Am J Neuroradiol 2012;33:407-14 CrossRef Medline

15. Comella CL, Leurgans S, Wuu J, et al; Dystonia Study Group. Rating scales for dystonia: a multicenter assessment. Mov Disord 2003;18: 303-12 CrossRef Medline

16. Schiffmann R, van der Knaap MS. Invited article: an MRI-based approach to the diagnosis of white matter disorders. Neurology 2009;72:750-59 CrossRef Medline

17. McLachlan MS, Williams ED, Fortt RW, et al. Estimation of pituitary gland dimensions from radiographs of the sella turcica: a postmortem study. Br J Radiol 1968;41:323-30 CrossRef Medline

18. Doraiswamy PM, Potts JM, Axelson DA, et al. MR assessment of pituitary gland morphology in healthy volunteers: age- and gender-related differences. AJNR Am J Neuroradiol 1992;13:1295-99 Medline

19. Kwee RM, Kwee TC. Virchow-Robin spaces at MR imaging. Radiographics 2007;27:1071-86 CrossRef Medline

20. Murray RA, Maheshwari HG, Russell EJ, et al. Pituitary hypoplasia in patients with a mutation in the growth hormone-releasing hormone receptor gene. AJNR Am J Neuroradiol 2000;21:685-89 Medline

21. Mehmood S, Hoggard N, Hadjivassiliou M. Gordon Holmes syndrome: finally genotype meets phenotype. Pract Neurol 2017;17: 476-78 CrossRef Medline
22. Synofzik M, Gonzalez MA, Lourenco CM, et al. PNPLA6 mutations cause Boucher-Neuhauser and Gordon Holmes syndromes as part of a broad neurodegenerative spectrum. Brain 2014;137:69-77 CrossRef Medline

23. Salvador F, Garcia-Arumí J, Corcóstegui B, et al. Ophthalmologic findings in a patient with cerebellar ataxia, hypogonadotropic hypogonadism, and chorioretinal dystrophy. Am J Ophthalmol 1995; 120:241-44 CrossRef Medline

24. Malhotra HS, Garg RK, Vidhate MR, et al. Boomerang sign: clinical significance of transient lesion in splenium of corpus callosum. Ann Indian Acad Neurol 2012;15:151-57 CrossRef Medline

25. Bulakbasi N, Kocaoglu M, Tayfun C, et al. Transient splenial lesion of the corpus callosum in clinically mild influenza-associated encephalitis/encephalopathy. AJNR Am J Neuroradiol 2006;27: 1983-86 Medline

26. van der Knaap MS, Valk J, de Neeling N, et al. Pattern recognition in magnetic resonance imaging of white matter disorders in children and young adults. Neuroradiology 1991;33:478-93 CrossRef Medline

27. Bobele GB, Garnica A, Schaefer GB, et al. Neuroimaging findings in Alexander's disease. J Child Neurol 1990;5:253-58 CrossRef Medline

28. van der Knaap MS, Smit LM, Barth PG, et al. Magnetic resonance imaging in classification of congenital muscular dystrophies with brain abnormalities. Ann Neurol 1997;42:50-59 CrossRef Medline

29. Schmahmann JD, Smith EE, Eichler FS, et al. Cerebral white matter: neuroanatomy, clinical neurology, and neurobehavioral correlates. Ann N Y Acad Sci 2008;1142:266-309 CrossRef Medline

30. van der Knaap MS, Naidu S, Breiter SN, et al. Alexander disease: diagnosis with MR imaging. AJNR Am J Neuroradiol 2001;22:541-52 Medline

31. Arber CE, Li A, Houlden $\mathrm{H}$, et al. Review: insights into molecular mechanisms of disease in neurodegeneration with brain iron accumulation-unifying theories. Neuropathol Appl Neurobiol 2016;42: 220-41 CrossRef Medline

32. Hogarth P. Neurodegeneration with brain iron accumulation: diagnosis and management. J Mov Disord 2015;8:1-13 CrossRef Medline

33. Almeqdadi M, Kemppainen JL, Pichurin PN, et al. Phenotypic variability of c.436delC DCAF17 gene mutation in Woodhouse-Sakati syndrome. Am J Case Rep 2018;19:347-53 CrossRef Medline 